\title{
The Psychology Postgraduate System in Brazil: Current Characteristics and Challenges for the Area ${ }^{1}$
}

\section{O Sistema de Pós-graduação no Brasil: Características Atuais e Desafios à Área.}

\author{
Antonio Virgílio Bittencourt Bastos ${ }^{\mathrm{a}}$, Gerson Yukio Tomanarib, Zeidi Araujo Trindade ${ }^{\mathrm{c}} \&$ Maria \\ Amália Pie Abib Andery ${ }^{\mathrm{d}}$ \\ ${ }^{a}$ Universidade Federal da Bahia, Salvador, BA, Brazil, ${ }^{b}$ Universidade de São Paulo, São Paulo, SP, Brazil, \\ ${ }^{c}$ Universidade Federal do Espírito Santo, Vitória, ES, Brazil \& ${ }^{d}$ Pontifícia Universidade Católica de São Paulo, \\ São Paulo, SP, Brazil
}

\begin{abstract}
This text is a characterization of the Psychology Postgraduate System in Brazil, presenting indicators of its growth in recent years, of its current geographical distribution, of its research lines, and of the grades awarded in the last Triennial evaluation of 2013. This characterization underlies a set of reflections regarding the challenges for the area from the guidelines established by the National Postgraduate System Plan (PNPG) 2011-2020. These challenges include: internationalization, interdisciplinarity, the link with basic education, the reduction of regional disparities, and the differentiation between academic and professional qualification. The text also focuses on the continuous and necessary improvements in the evaluation process conducted by the Coordination for the Improvement of Higher Education Personnel (CAPES). These reflections seek to provide a basis for the management of the Psychology Postgraduate System in Brazil in the coming years.

Keywords: CAPES, PNPG, psychology, postgraduate, internationalization, Brazil.
\end{abstract}

\begin{abstract}
Resumo
O presente texto faz uma caracterização do sistema de Pós-Graduação em Psicologia no Brasil, oferecendo indicadores do seu crescimento nos últimos anos, da distribuição geográfica vigente, dos fenômenos tomados como objetos de investigação nas suas linhas de pesquisa e das notas atribuídas na última avaliação trienal de 2013. Tal caracterização embasa um conjunto de reflexões sobre os desafios para a Área a partir de diretrizes fixadas pelo Programa Nacional de Pós-Graduação (PNPG) 2011-2020, tais como: internacionalização, interdisciplinaridade, vínculo com a educação básica, redução das assimetrias regionais, diferenciação entre a formação acadêmica e profissional. Focaliza-se, também, os aprimoramentos contínuos e necessários do processo de avaliação conduzido pela Coordenação de Aperfeiçoamento de Pessoal de Nível Superior Capes. Tais reflexões buscam embasar a gestão da Área nos próximos anos.

Palavras-chave: CAPES, PNPG, psicologia, pós-graduação, internacionalização, Brasil.
\end{abstract}

The Brazilian Postgraduate System has been guided by the National Postgraduate System Plans (PNPGs) since 1975. The sixth edition is the first PNPG with projection of actions over a decade (PNPG 2011-2020). These plans seek to strategically direct the postgraduate system to achieve important goals for the country in its quest for

Correspondence concerning this article should be addressed to Antonio Virgílio Bittencourt Bastos; Centro de Estudos Interdisciplinares para o Setor Público (ISP); Avenida Adhemar de Barros, Pavilhão 4, Campus Universitário, Ondina, CEP:40170-110. Tel/fax (71) 3263-6474. E-mail: virgilio@ufba.br.

The authors acknowledge the contributions made to the text by our colleagues Paulo Rogério Meira Menandro, Oswaldo Yamamoto, and Emmanuel Zagury Tourinho. economic and social development. Therefore, the PNPGs have served to guide the efforts, plans and actions of the institutions dedicated to research and the postgraduate system in the country.

The National Postgraduate System Plans have always considered the importance and centrality of science and technology as elements for economic transformation and overcoming the social problems that still affect our society. The expectation for the development of the Brazilian postgraduate system so that it can actively participate in the project to lead Brazil, within this present decade, to become the fifth economy of the world is clearly included in the VI PNPG 
(2011-2020). This project involves challenges related to qualitative and quantitative growth for the postgraduate system and the area of psychology.

From a quantitative perspective it will be necessary to increase the number of qualified master's and doctorate holders, for academic practice as well as other sectors, which will require the expansion of the system and the internal growth of courses. The need for quantitative growth of the system as a whole is associated with a second guideline, this being the reduction of regional disparities. To apply this guideline whilst simultaneously preserving the standards of quality for the system as a whole remains a challenge today. Another guideline of the VI PNPG is the differentiation between the academic courses, those focused on the qualification of researchers and professors, and the professional courses, those aimed at training specialists for the production market and the public sector. This implies the need to form partnerships with the non-academic sector, covering the generation of technology and competences. This differentiation configures specific projects, with different performance profiles of the graduates, who will be evaluated through their own indicators and those congruent with the nature of the course. The VI PNPG highlights the need for excellence of the system and for internationalization, with strong growth of Brazilian participation in international scientific production, producing an impact in the scientific community. There is expectation of greater interaction of the programs with the international scientific community at all levels. The growing valorization of publication in international circulation mediums should have an impact on evaluation, as well as the financial support for Brazilian journals with the potential for visibility and international impact. The VI PNPG also verifies the need to stimulate multi- and interdisciplinary experiences and to amplify effective collaboration for the development of basic education in the country.

A supplement of this Psicologia: Reflexão e Crítica in 2010 published the papers presented at the I Seminar Horizons for the Psychology Postgraduate System in Brazil with important considerations and suggestions for the area. Lo Bianco, Almeida, Koller, and Paiva (2010) analyzed the issue of internationalization of the postgraduate system; Féres-Carneiro, Bastos, Feitosa, Seidl-de-Moura, and Yamamoto (2010) discussed the shortcomings and conditions for the expansion of the postgraduate programs; Hutz, Rocha, Spink, and Menandro (2010) analyzed the intellectual production of the programs, and Tourinho and Bastos (2010) reflected on the challenges surrounding psychology postgraduate courses in Brazil. Despite recent texts, the data that support their reflections need to be continually updated, given the dynamics of growth and the transformations occurring in the Brazilian postgraduate system.

More recent work has aggregated reflections that identify challenges posed to the growth of the
Psychology Postgraduate System. Menandro, Tourinho, Bastos, and Yamamoto (2013) discussed the difficulties surrounding the integration between undergraduate and postgraduate qualification, a concern present throughout the history of the area. Yamamoto, Menandro, Tourinho, and Bastos (2012) discussed the widely debated issue regarding the requirements for scientific production, in a debate labeled productivism, due to the risk that such requirements place on the quality of research in the area. Bastos, Tourinho, Yamamoto, and Menandro (2011) analyzed the challenge of teacher qualification within the programs of the Psychology Postgraduate System, highlighting the difficulties they face in developing the competencies expected of a professor.

Thus, this text summarizes the proposals of the Psychology Area Coordination in CAPES for the coming years, based on the National Postgraduate System Plan guidelines (PNPG 2011-2020). The proposals consider the above recent analyses of the literature and also the data of the last evaluation of the programs performed by CAPES in 2013. Initially this article presents the current phase of the area, according to the latest evaluation data; then moves on to the analysis of the implications and of the enormous challenges that the VI PNPG guidelines represent for the strengthening of psychology in the Brazilian postgraduate system. These challenges include: 1) regional and intra-area disparities; 2) academic versus professional qualification; 3) internationalization; 4) interdisciplinarity; 5) the role of the Psychology Postgraduate System in elementary and high school education; and 6) the qualification of the periodic evaluations of the performance of the postgraduate system.

\section{The current phase of the area: from the diagnosis to the establishment of prospects}

The psychology stricto sensu postgraduate system is currently composed of 77 programs, considering the proposals for new courses approved during 2013 and implemented in 2014 . There are 50 programs with academic master's and doctoral courses, 25 programs with academic master's courses and only two programs with professionals master's courses. Today, there is twice the number of programs that existed in 2001. Thus, we have 127 stricto sensu postgraduate courses, 77 master's and 50 doctoral, the growth of which, over the period 1998-2013, is presented in Figure 1. These courses have approximately 5,000 master's students and 2,000 doctoral students enrolled. In 2011, the area qualified 1,130 master's and 326 doctoral candidates. These numbers are the result of a systematic growth over time that reflects the consolidation of research groups, especially in the context of the public higher education institutions.

Three points are central to characterize the distribution of the programs of the area: 1) the presence in different 
Bastos, A. V. B., Tomanari, G. Y., Trindade, Z. A., \& Andery, M. A. P. A. (2015). The Psychology Postgraduate System in Brazil: Current Characteristics and Challenges for the Area.

regions of the country, 2) the presence in different types of higher education institutions (HEIs), and 3) the diversity of sub-areas of psychology covered in the research lines of the programs. The concept of asymmetry - in the three dimensions seems to indicate horizons the area should move toward.

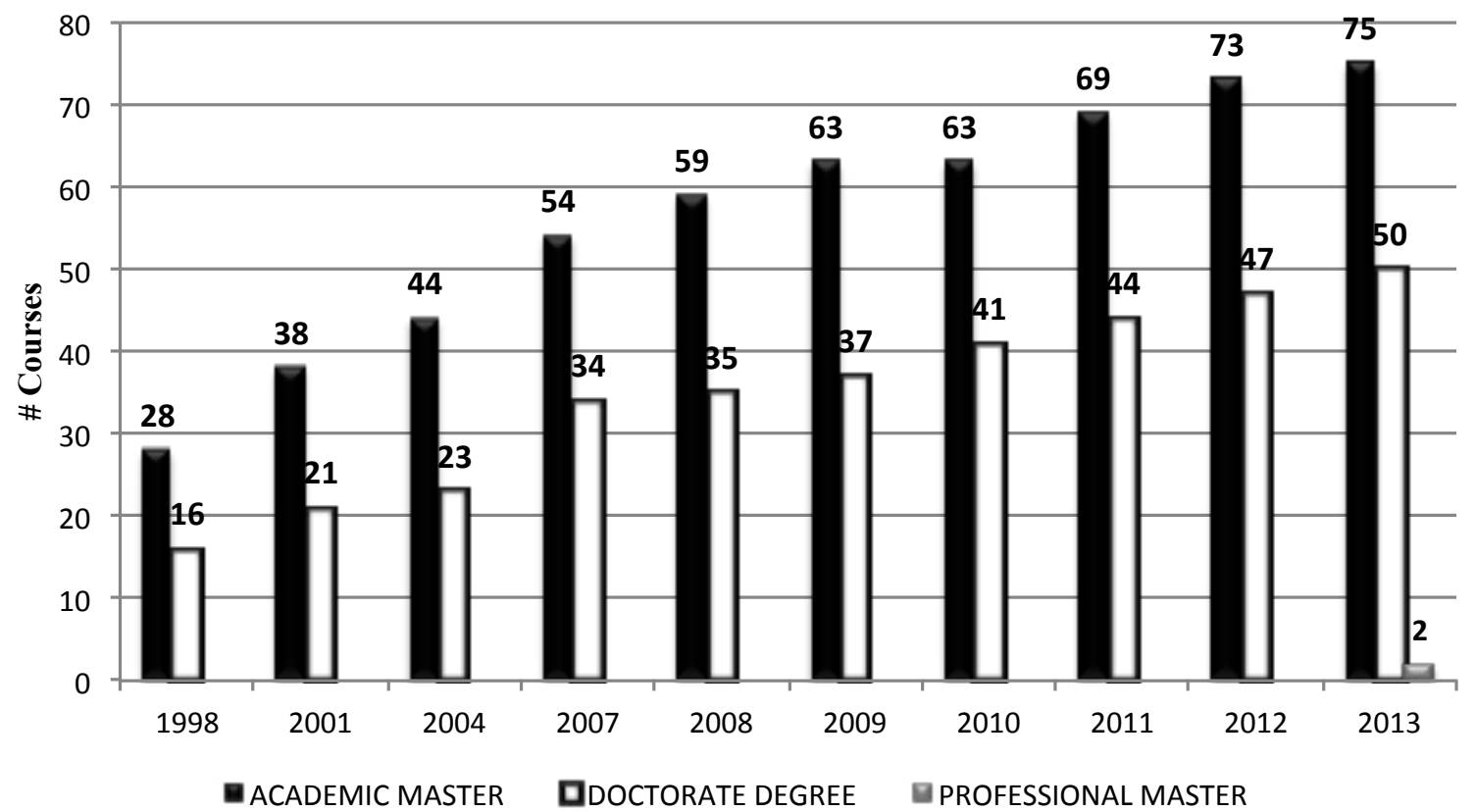

Figure 1. Growth in the number of academic master's, professional master's and doctorate Brazilian psychology postgraduate courses: 1998 to 2013.

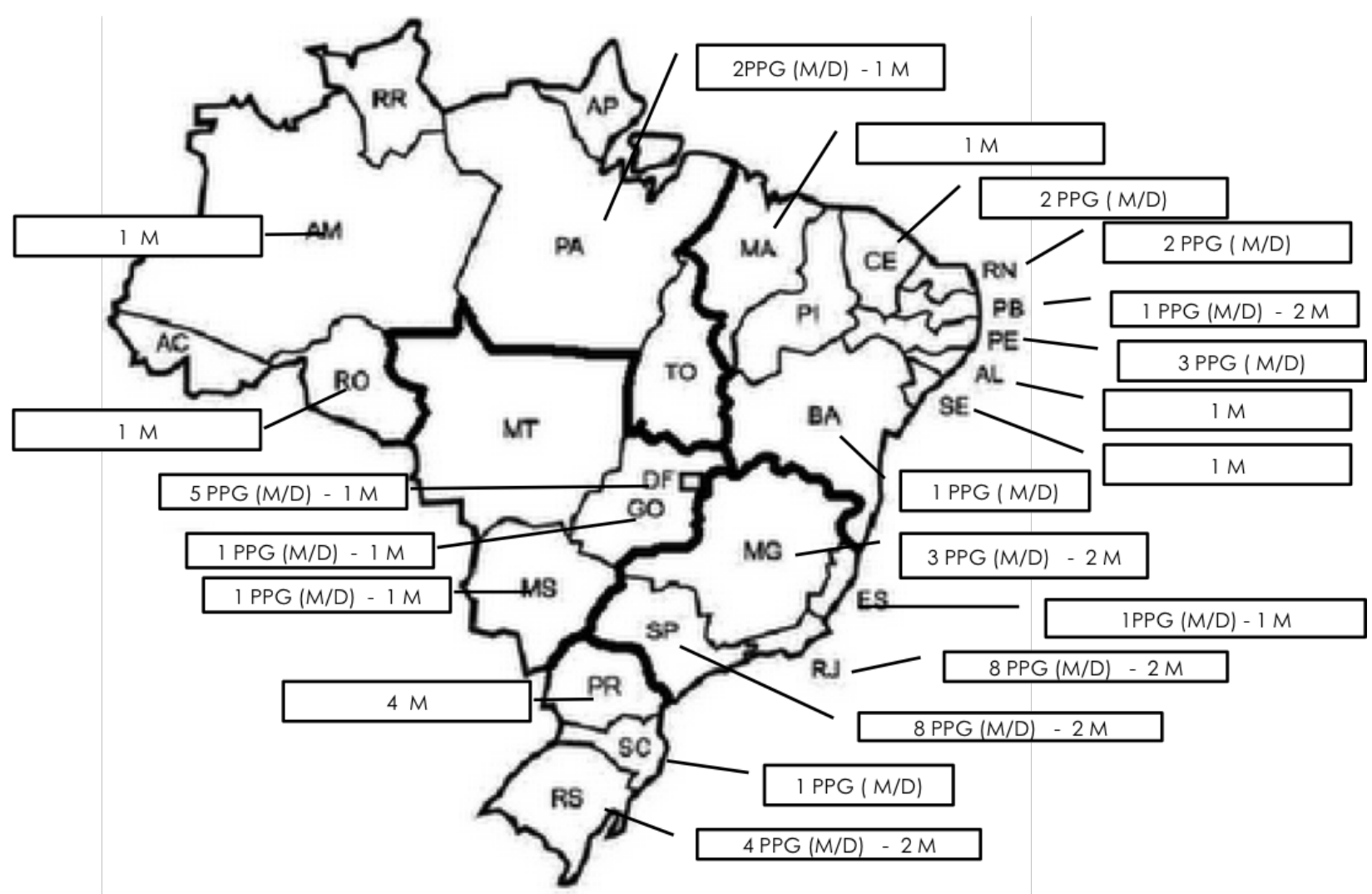

Figure 2. Distribution of Brazilian psychology postgraduate programs by states, in 2013. For each state, the number of Master's and Doctorate (M/D), only Academic Master's (M), and only Professional Master's (P) programs are 
The distribution of the programs and courses by geographical region appears to be asymmetric according to the pattern of the national postgraduate system, as shown in Figure 2. In this, it can be observed that $48.1 \%$ of the programs are in the Southeast, with $23.4 \%$ of the total programs in this area concentrated in the state of São Paulo. In regional terms, there is the following distribution: the Northeast $(18.2 \%)$, the South $(14.3 \%)$, the CentralWest $(13 \%)$, and the North (6.5\%). Half of the programs of the Central-West are in the Federal District and more than half of those of the Northern region are in the state of Pará. This profile of regional distribution is maintained when considering the courses, highlighting the fact that the concentration of doctoral courses in the Southeast increases to $54 \%$. The only two professional master's courses of the area are also found in the state of São Paulo.

Over the past four years, a reduction in regional disparities has been seen, with initiation of postgraduate programs in the states of Rondônia, Amazonas, Goiás, and Mato Grosso do Sul. In the Northeast, we now have master's courses in the states of Maranhão, Alagoas, and Sergipe. Another interesting aspect is the decentralization of the postgraduate system, which started hesitantly beyond the major urban centers of the state of São Paulo. Decentralization of the public university is beginning to be reflected in the appearance of proposals for psychology stricto senso postgraduate courses.

The Psychology Postgraduate System is concentrated in public higher education institutions $(71.4 \%$ of the programs are in public, federal or state HEIs). Among the private institutions it should be noted that the vast majority, that is almost all, of the programs are based in sectarian institutions. Private secular institutions have an extremely limited presence regarding academic courses; however they offer the only two professional master's courses of the area, both approved in the last triennium.

The area is characterized by internal disparities, when considering the various sub-areas and lines of research. In the set of programs of the area there are 236 active lines of research. These lines were categorized into 13 sub-areas, based on further description of the research line content. In cases in which lines of research involved clear interfaces between two sub-areas, lines were also categorized into a second sub-area. In all, the existing lines of research generated 289 classifications, with their distribution presented in Figure 3.

Three sub-areas concentrate $42.6 \%$ of the lines of research: Social Psychology, Clinical Psychology, and Basic Psychological Processes. With the addition of the sub-areas of Developmental Psychology and Health Psychology, the five sub-areas contain almost $2 / 3$ of the lines of research $(61.7 \%)$. Other sub-areas are underrepresented, which means that, in the area, there are few lines of research with the content that define them. Examples of the content with few mentions are: History of Psychology, Community Psychology, Forensic Psychology, and Traffic Psychology. It should be noted that relevant content, which may contribute to generate knowledge about current issues, does not even appear as a line of research, as with Environmental Psychology. It is important to note that a significant set of 21 lines of research (7.6\%) was included in a category "general/transversal issues."

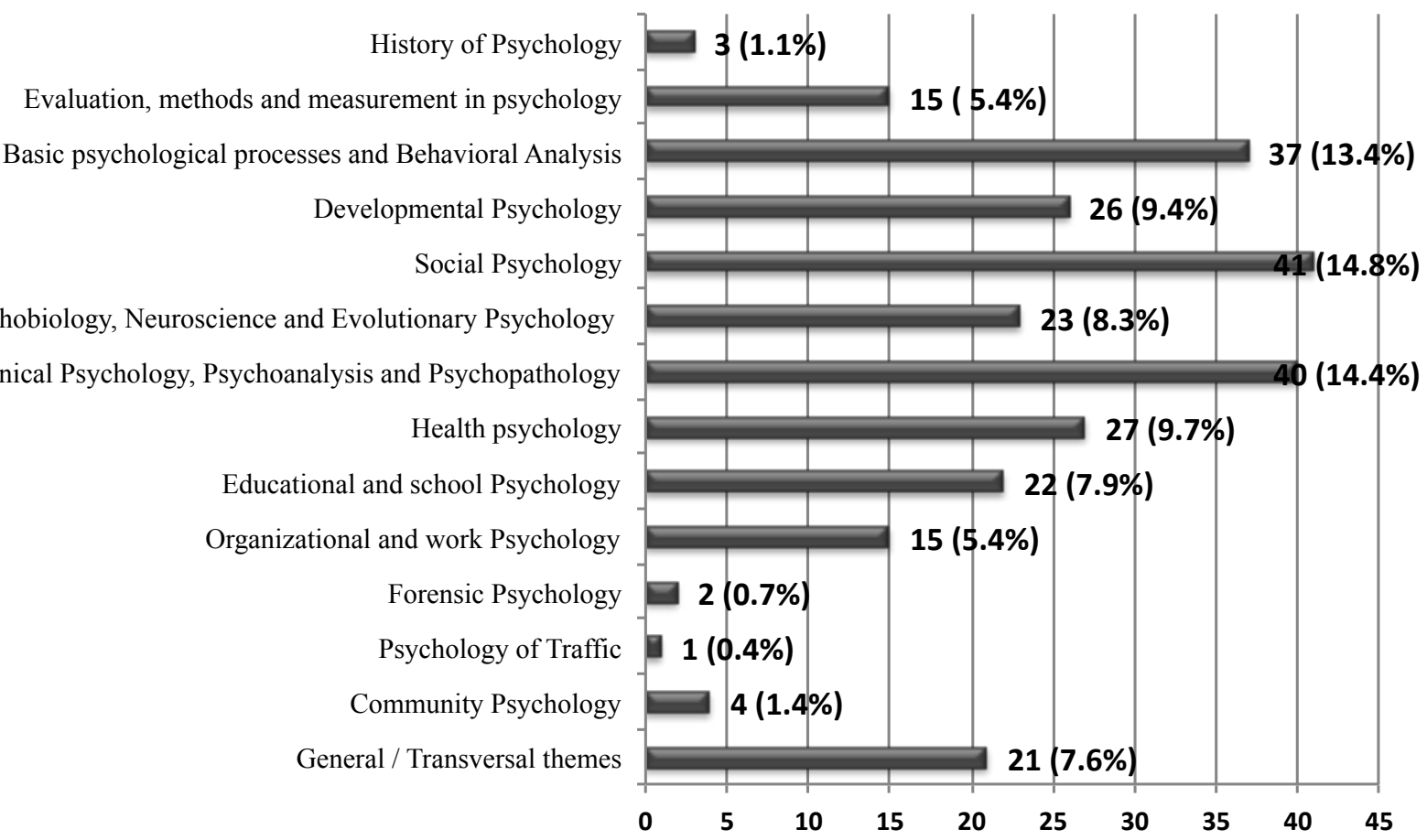

Figure 3. Distribution of the research lines of Brazilian psychology postgraduate programs, in 2012. 
Bastos, A. V. B., Tomanari, G. Y., Trindade, Z. A., \& Andery, M. A. P. A. (2015). The Psychology Postgraduate System in Brazil: Current Characteristics and Challenges for the Area.

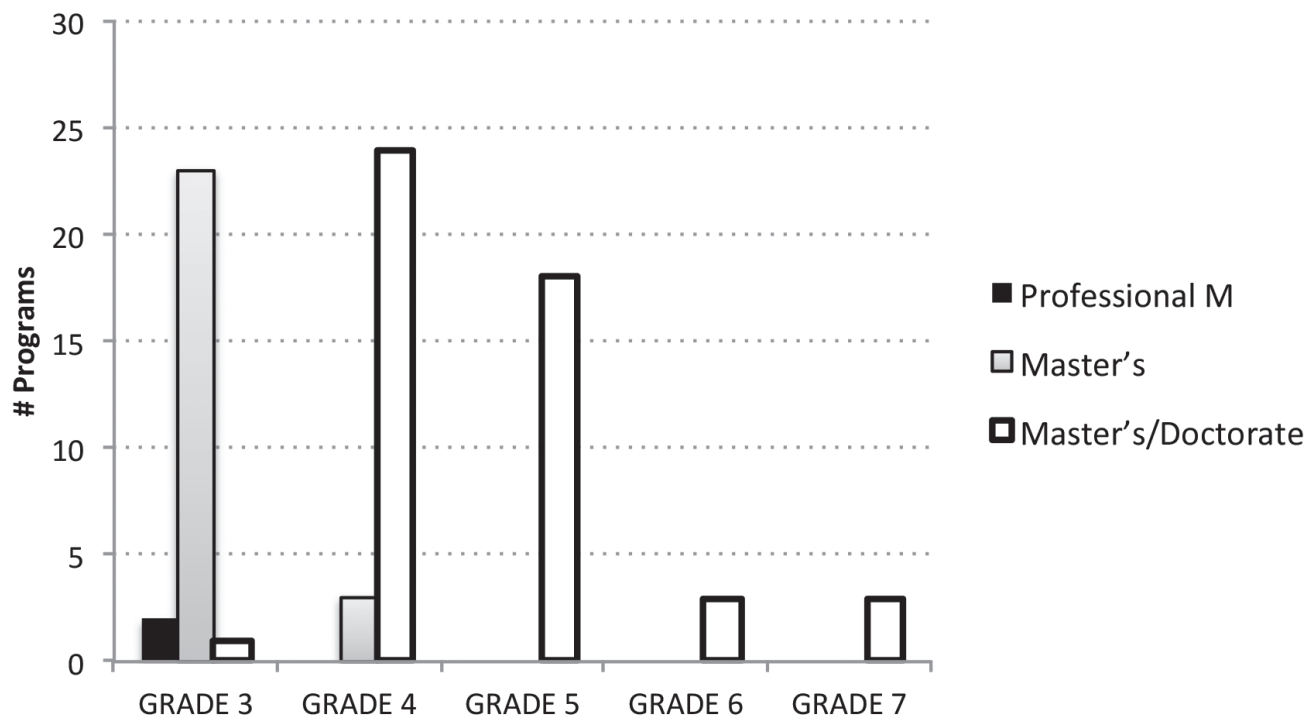

Figure 4. Number of Brazilian psychology postgraduate programs by grade in CAPES, in 2013.

These lines have a close interface with Social Psychology or Clinical Psychology, articulating the notion of subjectivization processes, i.e., constitution of the subject or construction of subjectivity with the cultural, social, political, and contemporary contexts.

In 1976 CAPES introduced systematic evaluation conducted by peers of the master's and doctoral courses. Initially, the evaluation occurred every two years. However, in recent years the evaluation has been conducted every three years, and from 2013 will be every four years. According to the current criteria, the courses are classified into concepts that range from 2 to 7, from a structured evaluation form with five issues (Proposal of the Program, Teaching Body, Student Body, Dissertations and Theses, Academic Production and Social Insertion). These issues open out into items and these into indicators, in which the areas can use a degree of freedom to contemplate their specificities. The process involves the establishment of various quantitative and qualitative data regarding the performance of the programs over the period evaluated. Reviewed by a pair of consultants, the results are submitted to a larger peer committee (in the last triennial evaluation the committee was composed of 25 members). The results of the evaluation of each area are submitted to the Scientific Technical Council of CAPES, this being the deliberative body.

Figure 4 presents the number of programs by grade, differentiating those with only master's courses from those with master's and doctorate courses. Many courses are included that were evaluated in 2013, as well as those authorized by CAPES in the final year of the 2010-2012 triennium, with their grades of authorization from the Scientific-Technical Council (CTC/ES).
As can be seen in Figure 4, of the 28 programs consisting solely of master's courses (26 academic and 2 professional) only three have a grade of 4 and the others a grade of 3. The programs with master's and doctoral courses, in turn, are distributed mostly in the grades of 4 (24 programs) and 5 (18 programs). There is only one program in this situation with a grade of 3 . On the other hand, only 6 programs of the psychology area have grades of 7 and 6 , an important indicator of the need for greater investment by the programs in their effective internationalization.

Next, some data are presented regarding the bibliographic production of the programs in the most recent evaluation, covering the 2010-2012 triennium, some of which are compared with the previous triennium (2007-2009).

In the last triennial review 13,896 items were included, of which 2,132 had to be disregarded due to problems with the records forwarded by the programs (absence, insufficiency or inadequacy of information) that prevented their evaluation. Therefore, a population of 11,764 items was considered. The Qualis Periodicals ${ }^{2}$ and the evaluation scores, constructed by the commission of the area, of books and chapters were used for the qualification of the items. All the indicators presented below refer to the production of the permanent professors (PPs) of the programs, since the production of collaborators and visitors is not calculated in the construction of the performance indicators.

\footnotetext{
All journals, national and international, in which there was at least one publication by professors and/or students of one of the area's programs are evaluated based on criteria and allocated into one of seven concepts: A1 and A2 (international standard), B1, B2, B3, B4, B5 (different quality levels of journals of national coverage). In the $\mathrm{C}$ category are the journals that do not meet the criteria and are not classified for evaluation purpose. Qualis is updated every year after the registration, by the programs, of their annual bibliographical production.
} 
In the 2010-2012 triennium, 7,373 articles were published in scientific journals (which represents an increase of $53.4 \%$ in relation to the 4,807 for the 2007 2009 triennium). This signifies a mean of 34.6 articles per program/year (compared to $25.0 / \mathrm{p} / \mathrm{y}$ in the previous triennium). This volume of production represents a mean of 2.5 articles per PP/year, a rate that reveals the progressive increase in production of the area $(1.8 / \mathrm{PP} / \mathrm{year}$ in the 20042006 triennium and 1.9 in the 2007-2009 triennium). This mean rate of article production hides a great variability: there is a group of four programs (all newly implemented) with a triennial mean of less than one article/PP/year and seven programs with rates that exceed 4 articles/PP/year.

The quality of the published articles, considering the Qualis of the Area, can be measured by the following indicators: a) the mean value of published articles was 57.7 points (on a scale in which the maximum value is 100, which corresponds to the A1 periodicals); b) the mean value of the articles by program varied between a minimum of 32.3 and a maximum of 82.5 points, with $42 \%$ of the programs presenting means equal to or higher than 60 and ten programs presenting means greater than 70 points.

The production of books and chapters in the 2010-2012 triennium totaled 4,391 items, exceeding the total for the 2007-2009 triennium (3,227 items), which corresponds to a mean of 20.6 items per program/year (16.8 in the triennium 2007- 2009) and 1.5 or books or chapters per $\mathrm{PP} /$ year, numbers close to the means of the previous triennium (1.3/PP/year). This production also presents variability: 21 programs stand out with mean numbers of books or chapters per PP that exceed 2.0 items per PP/ year, while the other six programs have means lower than 0.5 items per PP/year. Regarding the quality of the books and chapters published, based on the evaluation criteria used in this triennium and the four-level scale adopted (L1 to L4), the mean score of the area was 50.8 (47.3 in the triennium 2007-2009), also considering a maximum value of 100 points. Twelve programs presented a mean item score above 70 points, a score that corresponds to items evaluated as L3.

Considering articles and books/chapters together, a mean of 55.2 items/program/year was verified, which corresponds to 4.1 items/PP/year, exceeding the mean of the previous two trienniums (3.2). Again this mean hides a great variability that ranged from 0.3 to 9.0 items $/ \mathrm{PP} /$ year. A total of 34 programs exceeded the level of 4 items/ $\mathrm{PP} / \mathrm{year}$, with seven in the range of 5 to 6 items and ten exceeding 6 items/PP/year. The production profile is also variable regarding the relevance of articles and books/ chapters in the total production of the programs. Overall, $62 \%$ of the items produced in the 2010-2012 triennium were articles, indicating an increase in the proportion of this type of production regarding the total articles published compared to the previous triennium ( $58.9 \%$ of articles). In five programs the proportion of articles exceeded $80 \%$ and in the other 16 exceeded $70 \%$. The proportion of books and chapters corresponded to $38 \%$ of the total production of items in the area. It can be observed, however, that in 16 programs, the percentage of published books and chapters exceeded $50 \%$ of the total items.

Considering the Table of Best Production ${ }^{3}$ (Table 1) used in the area, which fixes a maximum of four items per PP/year for each program, it appears that in the 2010-2012 triennium, seven programs exceeded the ceiling just with their production articles. Taking into account articles, books and chapters, 34 programs exceeded the ceiling and had items discarded for calculating the contribution of each permanent professor per year and nine other programs reached more than $90 \%$ of the item total for their ceiling. Only seven programs presented production of less than $50 \%$ of the ceiling. Therefore, compared to the 2007-2009 triennium, there was a significant advance in the quantity of quality items published.

Given the volume and the quality of production of scientific articles, books and chapters, and the ceiling of the Table of Best Production, an overall score was calculated for the mean contribution of each permanent professor/ year for the program. In the 2010-2012 triennium, the mean score in the area was 221.2 points (which is to say that each professor is contributing, on average per year, approximately two A1 articles and one B5 article). This mean represents a significant increase compared to that of 145.6 points in the 2007-2009 triennium. The median of the group was 235 points. There is great variability in the performance of the programs, ranging from 42.3 to 371.1 points per permanent professor/year.

The bibliographic production of the programs of the area is primarily directed toward national mediums, whether scientific journals or books. In the 2010-2012 triennium, the mean percentage of items published internationally was $14 \%$, while in the 2007-2009 triennium this was $13.4 \%$. In the 2010-2012 evaluation, four programs presented more significant rates of internationalization of their production (above 50\%), while another 11 advanced and achieved percentages higher than the mean of the area $(20 \%)$.

Another important factor is the presence of items published exclusively by students in the general production of the programs. In the 2010-2012 triennium, 1,307 items were published exclusively by students. In the mean of the programs, $10.6 \%$ of the items were exclusively from students. This percentage markedly varies, from programs where there is no exclusive student publishing (especially the newer and more recently implemented ones) to the case of three programs in which student publishing exceeds one-third of the programs' total production (in one of them this percentage reached $41.8 \%$ ).

This is a device adopted by the Psychology Area to limit the number of published items that will be considered for purposes of evaluation of the program. It seeks to stimulate quality of production rather than a productivist race that favors quantity. All the items produced in a program are hierarchical and those that go beyond the planned ceiling are disregarded (4 items per permanent professor per year). 
Bastos, A. V. B., Tomanari, G. Y., Trindade, Z. A., \& Andery, M. A. P. A. (2015). The Psychology Postgraduate System in Brazil: Current Characteristics and Challenges for the Area.

Table 1

Indicator Means for the Bibliographic Production of Brazilian Psychology Postgraduate Programs by Grades 7 and 6, 5, 4, 3 and Area, According to the 2010-2012 CAPES Triennial Evaluation

\section{Classification of the Programs}

\begin{tabular}{|c|c|c|c|c|c|}
\hline Items & 7 and 6 & 5 & 4 & 3 & Area \\
\hline Mean number of articles & 188.6 & 161.9 & 91.7 & 41.6 & 106.0 \\
\hline Mean number of chapters and books & 70.4 & 93.8 & 67.0 & 22.6 & 63.5 \\
\hline Mean number of articles, chapters. and books & 259.0 & 255.7 & 158.7 & 64.2 & 169.5 \\
\hline $\begin{array}{l}\text { Mean quality of the production in articles classified as } \\
\mathrm{A} 1, \mathrm{~A} 2 \& \mathrm{~B} 1\end{array}$ & 78.4 & 72.6 & 58.4 & 51.9 & 62.2 \\
\hline $\begin{array}{l}\text { Mean quality of the production in books or chapters } \\
\text { classified as superior level }\end{array}$ & 64.1 & 61.0 & 55.3 & 48.4 & 55.9 \\
\hline Mean contribution per PP/year w/ TBP & 307.3 & 281.1 & 215.6 & 131.1 & 218.0 \\
\hline Items published abroad (\%) & 42.6 & 16.4 & 12.2 & 5.0 & 13.8 \\
\hline Quantitative growth (\%) & 27.4 & 35.3 & 23.8 & 10.7 & 23.8 \\
\hline Qualitative growth (\%) & 12.2 & 11.2 & 10.0 & 9.7 & 10.2 \\
\hline PP with production above floor level (\%) & 93.9 & 95.0 & 89.7 & 76.3 & 87.6 \\
\hline Production of the $20 \%$ most productive PP $(\%)$ & 41.2 & 41.0 & 40.9 & 46.7 & 41.9 \\
\hline Co-authored professor - professor (\%) & 8.7 & 7.8 & 5.5 & 8.0 & 6.8 \\
\hline Co-authored professor- student (\%) & 45.4 & 38.8 & 31.7 & 21.7 & 31.9 \\
\hline Mean score of technical production & 52.0 & 52.8 & 38.3 & 30.5 & 40.8 \\
\hline
\end{tabular}

Regarding the distribution of production by permanent professors, we found that a mean of $42.1 \%$ of published papers were concentrated in $20 \%$ of the faculty (rate identical to that of the 2007-2009 triennium). This percentage varies from a minimum of $24.4 \%$ (one program) to a maximum of $60 \%$ (four programs). Twenty programs presented percentages below $35 \%$, an indicator considered very good by the area. Another important indicator is that, in the set of programs, a mean of $87 \%$ of the professors exceeded the floor defined by the area (at least 70 points/ $\mathrm{PP} /$ year). There were three newly implemented programs, with percentages below $50 \%$.

The production of the area is characterized more by the presence of co-authorships among professors and students than by co-authorships among professors of the same program. In the 2010-2012 triennium, the mean co-authorship between professors was $6.7 \%$ of items published (ranging from one program in which $37.5 \%$ of its items were collaborations among professors to three programs that did not present any co-authorship). There was a mean professor-student co-authorship of $31.8 \%$ (a significant increase compared to the $17.6 \%$ of the previous triennium). There is a block of six programs in which the items co-authored with students surpassed $50 \%$ of its production; conversely, seven programs had less than $10 \%$ of their items published jointly by professors and students.

Finalizing the presentation of data related to the academic production of the programs in the 2010-2012 triennial evaluation, Table 1 presents a set of bibliographic production indicators of the area considered in the evaluation, grouped on the basis of grades obtained by the programs and the overall mean of the area. These data allow us to analyze the bibliographic production indicators in quantitative terms (mean number of items, 
number of chapters and books, and total corresponding items). They permit, in qualitative terms, the analysis of the bibliographic production of the programs according to the Qualis Periodicals of the Area and the evaluation of books, on a 0-100 scale indicator (mean quality of the article production, mean quality of the chapter and book production).

The mean contribution of each permanent professor (PP), per year, is shown following the Table of Best Production (TMP), with this indicator being scaled from 0 to 400 . The percentage of bibliographic production published in international media is indicated in the table. The quantitative evolution of the production and its corresponding qualitative evolution are shown as growth percentages, comparing the 2010-2012 triennium with the 2007-2009 triennium. The percentage of permanent professors whose production in the triennium was above the floor limit is also shown (considering a floor limit of 70 points per PP/year or 210 points over the triennium). The percentage of bibliographical production corresponding to the production of the $20 \%$ of the most productive professors is highlighted as an indicator of concentration of the production of the programs. Of the total bibliographical production, the percentages derived from the collaborations between professors of the program and between professors and students are shown. Finally, on a scale of 0 to 100 , the table presents the mean score of the technical production of the programs, having evaluated a subset of 15 items of technical production indicators, described by the programs as the most significant of the triennium. As can be seen in the set of all indicators, the programs with different grades present different scores, which shows that the effective use of the indicators contributes to differentiate the programs of different qualities.

\section{Challenges posed for the management of the Psychology Postgraduate System}

Given the PNPG guidelines and the enormous challenges they represent, this segment presents reflections on points that we believe are essential for strengthening the Psychology Postgraduate System over the coming years.

\section{Regional and intra-area disparities}

The emergence of proposals for postgraduate courses, as is known, depends on the level of maturity and consolidation of the research activities within the HEIs. They must present specific institutional development policies that consider research and the postgraduate system as central.

The Coordination of the Area has presented little action directed toward the stimulation of new courses and reduction of regional disparities, restricting itself to technical support for groups that are already structured for the submission of new proposals. Considering that we do not have postgraduate programs in six Brazilian states (Tocantins, Mato Grosso, Acre, Amapá, Roraima, and Piauí), some inducing actions become necessary. It is necessary within these states: a) to perform an assessment of the institutions that already offer psychology undergraduate courses for the identification of possible active research groups that could function as embryos for future postgraduate programs; and b) to stimulate, among the psychology programs, via recognition as an important impact indicator, actions aimed to strengthen research in institutions that do not have postgraduate programs.

Regarding the intra-area disparities, we can encourage researchers, from various institutions, to cover important remaining gaps. Three sub-areas, which cover very current issues, constitute the major gaps: Traffic Psychology, Sports Psychology, and Environmental Psychology. It is possible to provide more effective support to research groups that work in these sub-areas within the programs. Finally, it should be noted that the induction of actions, however important, cannot lead to a lowering of the standards of quality in the approval of new courses that the area has developed and consolidated over time.

\section{Academic and professional qualification in the context of the Psychology Postgraduate System}

In 2012, only two proposals for professional master's course presented sufficient merit for their approval; these courses are in the initial stage of implementation. There is, however, a clear understanding that professional courses are extremely necessary in the area, not only due to the applied fields that include psychology in virtually all professional domains (health, education, management, labor, environment, traffic, social assistance, and others) but also due to the magnitude of social problems in which assessment and intervention require the contribution of psychology. The increasing inclusion of psychology in public health and social assistance policies strongly increases the demand for professional qualification at the postgraduate level. Within the area, this need coexists with the idea that the provision of a professional course could lead to impairments in the evaluation of the academic courses, mainly because we have small programs considering the total number of professors linked to them.

To encourage the growth of professional courses in the area, it is essential to: a) continue highlighting, in all the events and contacts with the area, the importance of such courses for our postgraduate system, seeking to reduce doubts and uncertainties that limit the initiatives of the already consolidated academic programs to propose professional master's courses; b) review, within the margin of freedom that each area has to structure their evaluation form, the criteria (teaching body composition and division of production) that encourage the proposal of professional master's courses by HEIs that already offer academic courses; c) implement, as soon as possible, the review process of the nature of some programs of the area. 
Bastos, A. V. B., Tomanari, G. Y., Trindade, Z. A., \& Andery, M. A. P. A. (2015). The Psychology Postgraduate System in Brazil: Current Characteristics and Challenges for the Area.

Supported by a more careful diagnosis in the area, criteria can be identified that indicate programs in which their products bring them closer to professional courses. Some courses would certainly benefit in the evaluation process if their professional nature were clearly assumed.

\section{Internationalization of the Area}

The internationalization process of Brazilian scientific production has accelerated over the last decade and this has also occurred in the area of psychology. Some indicators taken from the SCImago Platform, analyzing the period from 1996 to 2011, are sufficient to attest to this fact. In terms of production volume, psychology occupies the $13^{\text {th }}$ place among the areas; this position falls to $20^{\text {th }}$ when considering the amount of citations as a parameter. In 1996 Brazilian psychology production represented $0.27 \%$ of world production; in 2011 it represented $2.17 \%$. International collaboration was $14.5 \%$ and needs to be expanded. With an h-index of 48, Brazilian psychology occupies the $21^{\text {st }}$ position among countries.

When examining the profile of the production of the programs of the area, a central feature that stands out is the fact that internationalization is very significant in the programs of some sub-areas (Experimental Psychology, Basic Processes, Psychobiology, Behavioral Neuroscience) with cases of programs in these sub-areas where the majority of the production (over 50\%) is in foreign journals of international scope. Conversely, there are sub-areas in which internationalization is far less significant: those that interface with the social sciences and applied areas, as they are focused on psychosocial problems of a local or regional reality. It is also interesting to note that internationalization has been growing regarding the production of books and chapters due to the increasing participation of national researchers in international research networks.

There is, however, huge space to expand the internationalization indicators in the area, which are not limited to bibliographic production abroad. The Area Coordination must assume the role of inducer, while recognizing that, among the consolidated programs with a grade of 5 , there are already high levels of internationalization, as revealed in the 2010-2012 triennial evaluation. This inducement will require: a) expansion of the spaces already used to discuss international performance standards in the area, using the various preexisting academic events; b) continued improvement of the indicators of internationalization used in evaluation of the programs, above all, seeking to obtain more accurate and comparable data regarding the extent of academicscientific interactions; c) clearer support for events that promote opportunities for articulation between national and international research groups (which has been carried out by means of the criteria used in the evaluation by the Program of Support for Events in the Country PAEP/CAPES); and d) signaling of the importance of solidification of the support defined and not provided by CAPES for two journals of the area that are committed to their internationalization.

\section{The issue of Interdisciplinarity}

Psychology, in its essence, articulates complex phenomena, which is reflected in our postgraduate system, in the definition of lines and in the composition of our teaching body. Its interfaces involve the field of biological sciences (e.g., Behavioral Analysis, Psychobiology, Psychopharmacology, Evolutionary Psychology, and Neuroscience); it has points of connection with the entire spectrum of Human and Social Sciences (Anthropology, Sociology, History, and Political Science); it is linked in different ways with the Health Area (Mental Health, Occupational Health, Health Psychology, Gerontology, Adherence to Treatment, Chemical Dependency, and Pain, among others); it connects with the entire spectrum of Applied Social Sciences (in the fields of Organizations, Work, Education, Communication, Traffic, Information Technology, Economics, and Law); and it reaches the domains of Literature, Language and the Arts. In the area of psychology, no restrictive criteria are adopted with regard to the composition of the teaching body of a postgraduate program according to its research area, considering only its relevance to the range of problems investigated in the lines of research in which it operates. To assume this interdisciplinary characteristic already exists is in line with the guidelines of the new PNPG. To advance, it is possible to deepen the differential treatment given to interdisciplinary programs, tentatively initiated in the previous triennial review, so that the interdisciplinary nature of a program of the area is not a detrimental factor in its evaluation. This may require us to: a) conduct a review of the criteria that structure the Qualis Periodical of the Area; b) implement, when defined by the Technical Scientific Council (CTC), the incorporation of programs currently integrated in the interdisciplinary area of which the profile is compatible with those of a similar nature that already exist in the area of psychology. The initial analysis of this issue has already been performed and some of the Interdisciplinary Area Programs that could easily migrate to the area of psychology have been identified in CAPES; and c) valorize the interdisciplinary events of the area in order to contribute to the strengthening of a perspective that considers the complexity of the phenomena for which psychology has to make contributions.

\section{The role of the Psychology Postgraduate System in elementary and high school education}

The interfaces between psychology and education are multiple and constitute part of the history of both fields. Educational issues are the investigation subject of research lines of 22 of the 77 programs of the area. These 
programs have uniquely contributed to the spontaneous demand for basic education in the cities, states or regions of origin. The thematic research areas of this interface are comprehensive and diverse and include: educational evaluation; cognitive and language development; human development; socio-cognitive development; psychosocial and socio-educational processes; social and institutional psychology; school psychology and educational processes; social skills and pedagogic practices; subjectivity, politics and social exclusion; educational practices and production of subjectivity; prevention and psychological intervention; and behavioral analysis in organizations, work and learning.

The challenge to CAPES to contribute to the improvement of the quality of basic education requires area initiatives that can expand its contribution in this domain, exceeding the timely and local/regionally delimited contribution, to assume a more active role given the challenging goals presented by the National Education Plan. Inducing actions that should be developed by the Coordination of the Area and by CAPES include: a) encouraging the establishment of research networks in different programs of the area that may provide the wide range of knowledge and technology generated by psychology to the formation of basic education teachers; b) seeking to include psychology in the qualification of teachers for early childhood education, considering the new policy of crèche dissemination throughout the country; c) making the contributions of psychology more visible in the field of Special Education; and d) making the contributions of psychology more visible in the field of Educational Evaluation. For all this, there are competences dispersed throughout various psychology programs that need to be united and potentiated. Research groups of ANPEPP that have these themes as an object can be invited to perform this systematization.

\section{The evaluation process: advances and qualification}

Over the past triennium, the Coordination of the Psychology Area was able to develop, due to the degree of freedom conferred by the general guidelines of the CTC for the evaluation of courses, a process that, in general, has proved very successful and appropriate to the specificity of the area. It can be affirmed that the evaluation performed is characterized as being discerning, rigorous and transparent. Discerning due to its reliance on a broad set of indicators that provide very clear parameters of expected performance, even in qualitative items; rigorous because the parameters require increasing performance levels from the programs, without stimulating stagnation; and transparent due to the clarity with which all the criteria and performance indicators are communicated to all programs.

The continuous improvement process of the evaluation throughout the 2010-2012 triennium ensured some important results: improvement of the indicators and procedures to evaluate technical production, social inclusion, and internationalization; greater valorization of the quality rather than quantity of the bibliographical production; valorization of the efforts of the programs to improve their performance regarding previous periods, identifying developments in their production compared to the 2007-2009 triennium; and differentiation in the evaluation of the bibliographical production between the programs with only master's courses and those with doctorate courses.

However, the entire evaluation process is subject to improvements that enable the fulfillment of the role of encouraging the quality of the system evaluated. In this sense, also using the level of freedom conferred by the general standards of the triennial evaluation, it is possible to state the main objectives to be achieved by the Coordination of the Psychology Area in CAPES:

1. To prepare conditions to perform, for the first time, the evaluation of professional master's courses in a way that respects the specificity of the qualification provided, in accordance with the legislation;

2. To stimulate, through discussion and evaluation, the concern of the academic programs of the area regarding the qualification or development of teaching competences, a dimension neglected in many programs due to the centrality that research and the corresponding bibliographic production assumed in the previous evaluation processes. There is a need to amplify the dissemination of the belief that a broader set of skills, which are not limited to research activities, is expected from graduates of a program (something basic, however, insufficient);

3. To continue emphasizing and valorizing the quality of the items produced, as a way to combat inevitable distortions that emerged in the system as a whole in relation to scientific productivity, where the quantity has often overtaken quality (this signifies the continuous introduction of improvements in the Qualis Periodical and in the evaluation of books);

4. To ensure evaluation of program graduates through a national survey, using a standardized instrument to ensure comparability of information, overcoming the current model which is based on information provided by the programs, in which the successful cases are often differentially emphasized (related to the advance necessary in the evaluation of the impact of the program).

In the context of the requirement for a broader and more general reflection on the whole system, in addition to the discussions surrounding the gaps of the evaluation, it is essential to evaluate the limits and possibilities of different evaluation models of the postgraduate system. In general we rely on a comparative model centered on the measurement of efficiency of the programs in achieving results related to qualification and production. There is no evaluation of efficacy, although it is known that even the support provided by CAPES (scholarships, for example) is not distributed evenly among the programs. Similarly, the impact evaluation performed is very fragile and limited. To seek elements in these three dimensions would appear 
to be necessary to construct a consistent evaluation system, considering the level already achieved by the postgraduate system in Brazil. Conversely, the exponential growth of postgraduação in Brazil requires that the current evaluation model is reviewed. It will not be possible to continue indefinitely with such a detailed and expensive model. So, it is desirable to think about the cost-benefit of the evaluation system and come up with a lean and efficient model.

\section{Final Considerations}

Psychology constitutes a medium-sized area in the National Postgraduate System (SNPG), growing at a moderate rate, although slower than the growth of the system as a whole (the growth of which is strongly driven by the interdisciplinary area). We are, however, the second largest area in the Human Sciences and the third in the School of Humanities, considering the number of courses. We have advanced in the last triennium in terms of geographical distribution, expanding our presence in the North and Central-West regions. However, we still have five states of the Federation without any psychology stricto sensu postgraduate courses. Our programs are mainly included in public higher education institutions (federal and state). The presence of private institutions is very low, especially in those with lucrative purposes, a framework that may change due to the trend observed in the presentation of proposals for new professional master's courses. Among the private HEIs, the vast majority of the programs are in confessional institutions, as in the case of Catholic universities.

Compared to the other areas, our courses are of small to medium size, taking as a parameter either the number of faculty or the number of students. Our graduates enter both the higher education system and the professional market, revealing that, although consisting only of programs of an academic nature (with the first two professional master's courses only approved in 2012), our courses also fulfill the qualification requirement for psychologists and other professionals to work in public and private institutions of different natures. With this, there is still a gap between the amount of master's and doctors that we qualify and the demand for professors to meet the significant growth of the psychology professional courses in Brazil in recent years. Considering the necessary introduction of psychology into college courses of other areas of knowledge that qualify other professionals, this discrepancy justifies the quantitative growth of our postgraduate system.

The area has some challenges posed by the 20112020 PNPG which will require a joint action from its Coordination in CAPES with the programs in order to: a) amplify the impact of their actions on the training of teachers and professionals working in basic education; b) achieve better differentiation of proposals for courses that are primarily directed toward the qualification of professionals from those directed toward the qualification of professors and researchers who will work in higher education; c) expand participation in the international scenario strengthening research networks, increasing exchanges between professors and students and, overall, increasing the divulgation of national research in qualified international mediums. For this it is necessary to expand the professionalization of our more important journals to publish in English and become indexed by major international databases; d) increase collaborations and partnerships between consolidated programs and new programs, particularly in the North and Central-West regions, to strengthen them and ensure their vertical integration, thus making a reduction of the regional disparities possible; and e) finally, as has been happening over recent years, the CAPES' Coordination of the Area will have to drive improvements in the evaluation process of the programs, including the ability to deal with more interdisciplinary programs, which are displaying a growing trend. For both, the Coordination of the Area and programs should continue articulating at different levels and spaces to collectively construct ways to strengthen research and the Psychology Postgraduate System in Brazil.

\section{References}

Bastos, A. V. B., Tourinho, E. Z., Yamamoto, O. H., \& Menandro, P. R. M. (2011). Formar docentes: Em que medida a pósgraduação cumpre esta missão? [Training teachers, to what extent the postgraduate systems fulfills this mission?] (Réplica 1). Revista de Administração Contemporânea, 15, 1152-1160.

Feres-Carneiro, T., Bastos, A. V., Feitosa, M. A. G., Seidl-deMoura, M. L., \& Yamamoto, O. H. (2010). Gaps, goals and conditions for expanding graduate systems in psychology in Brazil. Psicologia, Reflexão e Crítica, 23, 11-24.

Hutz, C. S., Rocha, M. L., Spink, M. J. P., \& Menandro, P. R. M. (2010). Profile, evaluation and intellectual production goals of graduate systems in psychology. Psicologia, Reflexão $e$ Crítica, 23, 25-34.

Lo Bianco, A. C., Almeida, S. S., Koller, S. H., \& Paiva, V. (2010). Internationalization of graduate systems in psychology: Profile and qualification goals. Psicologia, Reflexão e Crítica, 23, 1-10.

Menandro, P. R. M., Tourinho, E. Z., Bastos, A. V. B., \& Yamamoto, O. H. (2013). Graduate and undergraduate studies: Neighbors without affinity? Paidéia, 23, 187-196.

Tourinho, E. Z., \& Bastos, A. V. B. (2010). Challenges to graduate courses in psychology in Brazil. Psicologia, Reflexão e Crítica, 23, 35-46.

Yamamoto, O. H., Menandro, P. R., Tourinho, E. Z., \& Bastos, A. V. B. (2012). Produção científica e produtivismo: há alguma luz no fim do túnel? [Scientific output and productivism: is there some light at the end of the tunnel?] Revista Brasileira de Pós-Graduação, 9, 727-750. 